\title{
Physiological Effort in Submaximal Fitness Tests Predicts Weight Loss in Overweight and Obese Men with Prostate Cancer in a Weight Loss Trial
}

\author{
Andrew DFrugé ${ }^{1 *}$, John A Dasher ${ }^{2}$, David Bryan ${ }^{1}$, Soroush Rais-Bahrami ${ }^{3}$, Wendy Demark-Wahnefried ${ }^{1}$ \\ and Gary R Hunter
}

${ }^{1}$ Department of Nutrition Sciences, University of Alabama at Birmingham (UAB), USA

${ }^{2} U A B$ School of Medicine, Birmingham, Alabama, USA

${ }^{3}$ Department of Urology, UAB School of Medicine, Birmingham, Alabama, USA

${ }^{4}$ Department of Human Studies, UAB, Birmingham, Alabama, USA

*Corresponding author: Andrew D Frugé, PhD, RD, Department of Nutrition Sciences, University of Alabama at Birmingham (UAB), WTI 102V, 1824 6th Ave S Birmingham, AL, 35294, USA, Tel: 205-996-7367, Fax: 205-975-2592, E-mail: drewfruge@ gmail.com

\begin{abstract}
Background: Obesity and weight gain after the diagnosis of prostate cancer are associated with an increased risk of prostate cancer recurrence and mortality; individualized plans to help prostate cancer survivors maintain or lose weight may be beneficial for recurrence risk reduction. Herein, we explore whether gains in cardiovascular fitness predict successful weight loss in men participating in a weight loss trial (NCT01886677).

Methods: Forty men were randomized to receive twice-weekly in-person and telephone-based guidance on calorie-restricted diets and aerobic exercise to promote $\sim 0.91 \mathrm{~kg} /$ week weight loss, or wait-list control. Thirty-two men completed submaximal $\mathrm{VO}_{2}$ Treadmill Tests (TT), anthropometric measures and two 24-hour dietary recalls at baseline and follow-up. For this secondary analysis, study arms were combined and associations between baseline and longitudinal changes in physiological effort (PE, measured by heart rate during TT), predicted $\mathrm{VO}_{2 \max }$, caloric intake and weight loss were analyzed.

Results: Men lost $3.4 \mathrm{~kg}$ in $50 \pm 23$ days on the study. Multivariate linear regression indicated weight change was associated with change in PE at stage 2TT (Partial R = $0.635, p<0.001)$, days on study (Partial $R=-0.589, p=$ 0.002 ) and change in caloric intake (Partial $R=0.457, p=$ 0.019).

Conclusions: Untrained men experiencing elevated heart rates during stage $2 \mathrm{TT}$ at baseline were able to achieve greater weight loss over the study period; this association was strengthened by a decrease in PE at the same level
\end{abstract}

from baseline to follow-up concomitant with reduced caloric intake. Therefore, for these middle-aged and older men with lower aerobic fitness, exercise appears to be a key factor in achieving higher degrees of weight loss.

\section{Keywords}

Prostatic neoplasms, Weight loss, Obesity, Aerobic fitness, Exercise

\section{Introduction}

In 2016 , roughly 180,890 men were diagnosed with prostate cancer, and 26,120 men died from the disease [1]. Obesity is a known risk factor for aggressive prostate cancer and is associated with higher risk of recurrence $[2,3]$. Because obesity has increased at a greater rate in cancer survivors than the general United States adult population in recent years, with 2014 estimates indicting that $31.7 \%$ of cancer survivors are obese [4], practitioners are encouraged to support weight loss efforts that are both effective and sustainable for their patients [3]. Not surprisingly, the American Cancer Society guidelines on nutrition and physical activity for cancer survivors' first recommendation is to achieve and maintain a healthy weight by reducing high energy foods and increasing physical activity [5].

Lifestyle interventions in prostate cancer survivors

Citation: Frugé AD, Dasher JA, Bryan D, Rais-Bahrami S, Demark-Wahnefried W, et al. (2017) Physiological Effort in Submaximal Fitness Tests Predicts Weight Loss in Overweight and Obese Men with Prostate Cancer in a Weight Loss Trial. Int J Cancer Clin Res 4:083. doi.org/10.23937/2378-3419/1410083 Received: June 14, 2017; Accepted: October 14, 2017; Published: October 16, 2017

Copyright: (C) 2017 Frugé AD, et al. This is an open-access article distributed under the terms of the Creative Commons Attribution License, which permits unrestricted use, distribution, and reproduction in any medium, provided the original author and source are credited. 
have resulted in improved lifestyle behaviors [6], physical function, and quality of life [7]. Over the past two decades, guidelines for the treatment of overweight and obesity have endorsed the need for weight loss interventions to include guidance on diet, exercise and behavioral modification [8]. A recent review of weight loss interventions in prostate cancer survivors found that combined diet and exercise interventions were more effective than exercise alone for weight loss [9], though weight loss achieved through diet or exercise has shown similar benefits in chronic disease risk [10], inflammatory cytokines [11,12], and angiogenesis markers [13] in middle-age and older adults. It is known that caloric expenditure varies widely for similar activities in this study population; therefore, identifying predictive factors for better estimation of the energy costs of exercise is a priority set forth by the American College of Sports Medicine (ACSM) [14].

In previous studies, we have found that ease in locomotion during walking is positively related to total energy expenditure, activity related energy expenditure and non-exercise training activity related thermogenesis as measured with doubly labeled water after weight loss in overweight premenopausal women [15]. We have also found that ease of locomotion is inversely predictive of subsequent one-year weight gain [16]. Finally, we have shown that exercise training, either strength or aerobic training, induces improvements in ease of walking [17-19]. To our knowledge no one has studied the relationship between ease of locomotion, or its influence on weight change in men with prostate cancer. Herein, we pursue a secondary analysis of a randomized weight loss intervention in which there was substantial drop-in (voluntary weight loss) in the control group. We hypothesize that ease of locomotion, or physiological effort, will be associated with increased weight loss in men with prostate cancer participating in a presurgical weight loss trial.

\section{Methods}

\section{Setting and participants}

Men in this study had localized prostate cancer and participated in a presurgical weight loss trial between their time of diagnosis and radical prostatectomy [20]. Informed consent was obtained from all participants enrolled in the study, which was approved by the University of Alabama at Birmingham Institutional Review Board. Study participants had to have a Body Mass In$\operatorname{dex}\left(\right.$ BMI) $>25 \mathrm{~kg} / \mathrm{m}^{2}$ and have no medical conditions affecting weight status or physical activity ability, have received no other treatment for their prostate cancer, and have surgery occurring at least 23 days after study enrollment.

\section{Intervention}

Men completed all measures at their initial visit prior to randomization to the weight loss arm or a wait-listed control arm. The weight loss arm received guidance from a registered dietitian on a nutritionally adequate energy-restricted diet and daily aerobic exercise was prescribed and supervised by an exercise physiologist with the goal promoting $0.91 \mathrm{~kg}$ per week over the duration of the study [20].

\section{Measures}

Men completed dual energy $x$-ray absorptiometry (Prodigy, Lunar Radiation, Madison, WI), anthropometric measures and $\mathrm{VO}_{2 \text { submax }}$ Treadmill Tests (TTs) during their initial and follow-up visits. The TT began with the participant seated for five minutes. Heart Rate (HR), oxygen consumption, ventilation, and the respiratory exchange ratio were monitored continuously from the seated position prior to and during TTs, which progressed in four minute stages as follows: Stage 1) 3.22 $\mathrm{km} / \mathrm{hr}, 0 \%$ incline; Stage 2) $3.22 \mathrm{~km} / \mathrm{hr}, 4 \%$ incline; Stage 3) $4.83 \mathrm{~km} / \mathrm{hr}, 4 \%$ incline; Stage 4) $6.44 \mathrm{~km} / \mathrm{hr}, 4 \%$ incline; Stage 5) $6.44 \mathrm{~km} / \mathrm{hr}$, 8\% incline. Estimated max-

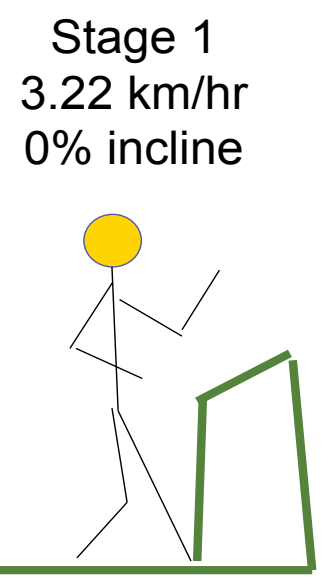

Figure 1: Baseline and follow-up VO presurgical weight loss trial. If $80 \%$ of estimated maximum heart rate was not reached in Stage 3 , the following stages ensued: Stage 4) $6.44 \mathrm{~km} / \mathrm{hr}, 4 \%$ incline; Stage 5) $6.44 \mathrm{~km} / \mathrm{hr}, 8 \%$ incline. 
imum HR was calculated by subtracting the participant age in years from 220 (Figure 1). When the participant reached $80 \%$ of estimated maximum HR per ACSM criteria, the assessment was complete [21]. Time was noted and treadmill speed and incline were lowered slowly to assure participant safety. Physiological Effort (PE) was defined as HR at the end of each TT stage.

The predicted $\mathrm{VO}_{2 \max }$ was estimated using the following equations validated in a similar population with a correlation of 0.66 and an estimate of $\mathrm{VO}_{2 \max }$ within $0.5 \mathrm{mlO}_{2} / \mathrm{kg} / \mathrm{min}$ : Predicted $\mathrm{VO}_{2 \max }=9.89+0.158 *$ est. $\max \mathrm{HR}\left(220\right.$ - age) + 0.478 Stage $2 \mathrm{TT} \mathrm{VO}_{2}-0.154 *$ Stage 2 TT HR.

Lean mass $\mathrm{VO}_{2 \max }=9.89+0.158 *$ est. $\max \mathrm{HR}(220$ - age) + 0.478 Stage $2 \mathrm{TT} \mathrm{VO}_{2}-0.154 *$ Stage $2 \mathrm{TT} \mathrm{HR} *$ Bodyweight/Fat-free mass.

Two-24 hour dietary recalls on non-consecutive days were obtained by a registered dietitian at both baseline and follow-up and entered into ASA24 (2011. Bethesda, MD: National Cancer Institute) [22,23], which derives caloric content of foods from the United States Department of Agriculture Food and Nutrient Database for Dietary Studies [24]. Average total calories at each time point were used for analyses.

\section{Statistical analysis}

One-way analysis of variance was used to determine differences between fitness test variables between study arms. Due to substantial drop-in by the waitlist group, the entire sample was further analyzed as a whole. Differences in anthropometric and fitness variables from baseline to follow-up were compared using paired t-tests. Pearson bivariate correlations were used to explore relationships between weight change and fitness test variables. Multiple linear regression was used to examine the independent effects of change in $\mathrm{HR}$ at stage 2 of the fitness test, days on study, and change in caloric intake on weight change. All statistical tests were conducted using IBM SPSS Statistics, Version 22.0 (IBM
Corp, Armonk, NY) and Bonferroni adjustment was used for multiple comparisons. Tests were considered statistically significant with a predetermined alpha of 0.05 .

\section{Results}

\section{Participants}

Thirty-two men completed baseline and follow-up treadmill tests and were included in this analysis. Participants had a mean age of 60 , ranging from 51 to 73 years. Twenty (62.5\%) men were Caucasian and 12 (28.5\%) were African American. Fourteen men were overweight (BMI $25 \mathrm{~kg} / \mathrm{m}^{2}-29.9 \mathrm{~kg} / \mathrm{m}^{2}$ ) and 18 were obese $\left(\mathrm{BMI} \geq 30 \mathrm{~kg} / \mathrm{m}^{2}\right)$ at baseline. At follow-up, only 11 men remained obese.

\section{Baseline and follow-up measures of adiposity and submaximal fitness tests}

Data are shown in Table 1. Fifteen of the 32 men in this secondary analysis were randomized to the weight loss group; however, the between-arm difference in weight change did not achieve significance $(p=0.058)$. The combined sample of men included in this analysis lost an average of $3.4 \mathrm{~kg}$ over $50 \pm 23$ days on study.

Men had low baseline aerobic fitness as calculated by $\mathrm{VO}_{2 \max }\left(25.0 \mathrm{mlO}_{2} / \mathrm{kg} / \mathrm{min}\right)$ and lean mass $\mathrm{VO}_{2 \max }(42.0$ $\mathrm{mLO}_{2} / \mathrm{kg}$ lean mass $/ \mathrm{min}$ ). Over the course of the study, participants increased $\mathrm{VO}_{2 \max }\left(0.8 \pm 1.5 \mathrm{mlO}_{2} / \mathrm{kg} / \mathrm{min}, \mathrm{p}\right.$ $=0.007)$ with no change in lean mass $\mathrm{VO}_{2 \max }(p=0.147)$. Measured HR and HR adjusted as a percentage of estimated maximum (220-age in years) slightly decreased from baseline to follow-up at stage 1 TT and stage 2 TT. No differences were observed between arms for changes from baseline to follow-up for PE or HR at any stage or predicted $\mathrm{VO}_{2 \max }$ (data not shown).

\section{Weight loss correlates}

Pearson correlation coefficients for weight change, physiological effort and $\mathrm{VO}_{2 \max }$ are shown in Table 2 . Weight loss was inversely associated with PE at stage

Table 1: Baseline and follow-up measures for men with prostate cancer participating in a presurgical weight loss trial $(n=32)$.

\begin{tabular}{|l|l|l|l|}
\hline & $\begin{array}{l}\text { Baseline } \\
\text { Mean } \pm \text { SD }\end{array}$ & $\begin{array}{l}\text { Follow-up } \\
\text { Mean } \pm \text { SD }\end{array}$ & $\begin{array}{l}\text { Change } \\
\text { Mean } \pm \text { SD }\end{array}$ \\
\hline Body weight $(\mathrm{kg})$ & $96.4 \pm 13.8$ & $93.0 \pm 13.3$ & $-3.4 \pm 3.9^{* * *}$ \\
\hline Body Mass Index $\left(\mathrm{kg} / \mathrm{m}^{2}\right)$ & $31.1 \pm 4.4$ & $30.0 \pm 4.2$ & $-1.1 \pm 1.3^{* * *}$ \\
\hline Percent body fat & $36.0 \pm 5.5$ & $34.6 \pm 5.5$ & $-1.4 \pm 1.9^{* * *}$ \\
\hline Caloric Intake & $1587 \pm 525$ & $1298 \pm 432$ & $289 \pm 667^{*}$ \\
\hline Stage 1 VO & $10.1 \pm 1.9$ & $9.6 \pm 2.0$ & $-0.4 \pm 1.7$ \\
\hline Stage 2 VO & $13.1 \pm 2.1$ & $12.5 \pm 2.2$ & $-0.5 \pm 2.2$ \\
\hline Stage 1 HR & $96.1 \pm 13.3$ & $90.1 \pm 13.3$ & $-6.0 \pm 9.9^{* *}$ \\
\hline Stage 2 HR & $106.8 \pm 14.2$ & $100.1 \pm 13.3$ & $-6.7 \pm 10.6^{* *}$ \\
\hline Stage 1\% of max HR & $0.601 \pm 0.086$ & $0.563 \pm 0.087$ & $-0.038 \pm 0.062^{* *}$ \\
\hline Stage 2\% of max HR & $0.667 \pm 0.088$ & $0.626 \pm 0.086$ & $-0.041 \pm 0.066^{* *}$ \\
\hline Predicted VO & $25.0 \pm 2.0$ & $25.8 \pm 2.1$ & $0.8 \pm 1.5^{* *}$ \\
\hline Predicted Lean mass VO & amax & $41.7 \pm 1.4$ & $-0.3 \pm 1.1$ \\
\hline
\end{tabular}

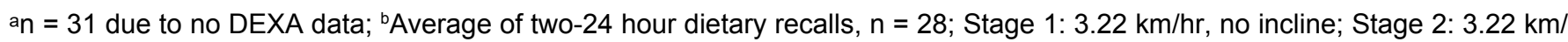
hr, $4 \%$ incline; ${ }^{*} p<0.01 ;{ }^{* *} p<0.05 ;{ }^{* * *} p<0.001$, significant at $p<0.004$. 


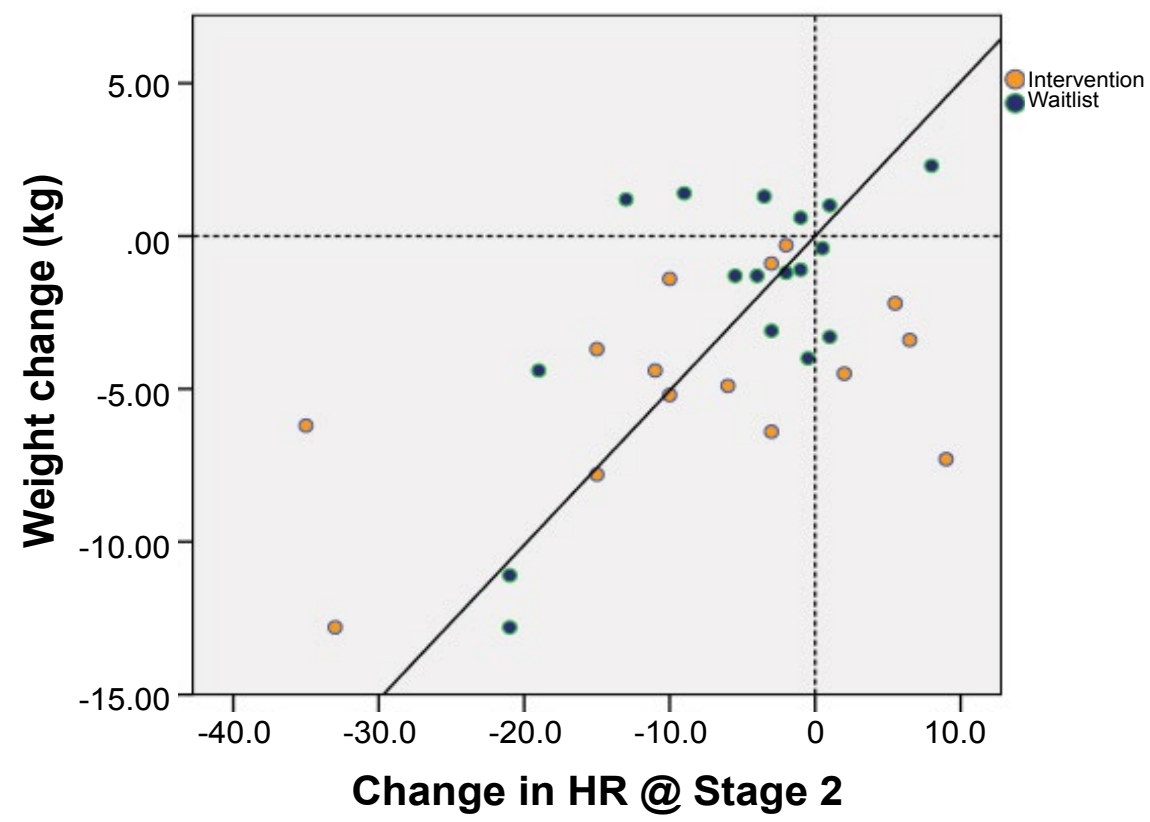

Figure 2: Weight loss correlates with decrease in heart rate in submaximal treadmill test Stage 2 TT $(p=0.0006)$ in men with prostate cancer participating in a presurgical weight loss trial $(n=32)$.

Table 2: Correlations between weight change, physiological effort and predicted $\mathrm{VO}_{2 \max }$ in men with prostate cancer participating in a presurgical weight loss trial $(n=32)$.

\begin{tabular}{|c|c|c|c|c|c|c|c|c|c|}
\hline & $\begin{array}{l}\text { Change } \\
\text { in weight } \\
(\mathrm{kg})\end{array}$ & $\begin{array}{l}\text { Baseline } \\
\text { HR @ } \\
\text { Stage } 1\end{array}$ & $\begin{array}{l}\text { Baseline } \\
\text { HR @ } \\
\text { Stage } 2\end{array}$ & $\begin{array}{l}\text { Baseline } \\
\mathrm{VO}_{2 \max }\end{array}$ & $\begin{array}{l}\text { Baseline } \\
\text { lean } \\
\text { mass } \\
\mathrm{VO}_{2 \max }\end{array}$ & $\begin{array}{l}\text { Change } \\
\text { in HR @ } \\
\text { Stage } 1\end{array}$ & $\begin{array}{l}\text { Change } \\
\text { in HR @ } \\
\text { Stage } 2\end{array}$ & $\begin{array}{l}\text { Change } \\
\text { in } \\
\text { predicted } \\
\mathrm{VO}_{2 \max }\end{array}$ & $\begin{array}{l}\text { Change } \\
\text { in lean } \\
\text { mass } \\
\mathrm{VO}_{2 \max }\end{array}$ \\
\hline Change in weight $(\mathrm{kg})$ & 1 & -0.260 & $-0.380^{*}$ & $0.406^{*}$ & -0.039 & $0.393^{*}$ & $0.576^{* *}$ & -0.241 & -0.058 \\
\hline Baseline HR @ Stage 1 & & 1 & $0.943^{* * *}$ & $-0.818^{* * *}$ & $0.375^{*}$ & $-0.370^{*}$ & -0.282 & -0.009 & -0.063 \\
\hline Baseline HR @ Stage 2 & & & 1 & $-0.791^{* * *}$ & $0.503^{* *}$ & $-0.396^{*}$ & $-0.453^{* *}$ & -0.033 & -0.107 \\
\hline Baseline Predicted $\mathrm{VO}_{2 \max }$ & & & & 1 & 0.136 & $0.356^{*}$ & 0.341 & -0.166 & -0.101 \\
\hline Baseline lean mass $\mathrm{VO}_{2 \max }$ & & & & & 1 & -0.134 & -0.251 & -0.264 & -0.294 \\
\hline Change in HR @ Stage 1 & & & & & & 1 & $0.826^{* \star *}$ & -0.154 & -0.078 \\
\hline Change in HR @ Stage 2 & & & & & & & 1 & -0.175 & -0.059 \\
\hline Change in predicted $\mathrm{VO}_{2 \max }$ & & & & & & & & 1 & $0.975^{\star *}$ \\
\hline
\end{tabular}

Stage 1: $3.22 \mathrm{~km} / \mathrm{hr}$, no incline; Stage 2: $3.22 \mathrm{~km} / \mathrm{hr}, 4 \%$ incline; an = 31 due to no DEXA data; ${ }^{*} p<0.01 ;{ }^{* *} p<0.05 ;{ }^{* * *} p<0.001$.

Table 3: Correlations between weight change and physiological effort as a percent of estimated maximum heart rate in men with prostate cancer participating in a presurgical weight loss trial $(n=32)$.

\begin{tabular}{|l|l|l|l|l|l|}
\hline & $\begin{array}{l}\text { Change in } \\
\text { weight (kg) }\end{array}$ & $\begin{array}{l}\text { Baseline \% of Max } \\
\text { HR @ Stage 1 }\end{array}$ & $\begin{array}{l}\text { Baseline \% of Max } \\
\text { HR @ Stage 2 }\end{array}$ & $\begin{array}{l}\text { Change in \% } \\
\text { of Max HR @ } \\
\text { Stage 1 }\end{array}$ & $\begin{array}{l}\text { Change in \% } \\
\text { of Max HR @ } \\
\text { Stage 2 }\end{array}$ \\
\hline Change in weight (kg) & 1 & -0.270 & $-0.398^{*}$ & $0.394^{*}$ & $0.583^{* * *}$ \\
\hline Baseline \% of Max HR @ Stage 1 & 1 & $0.947^{* * *}$ & $-0.351^{*}$ & -0.236 \\
\hline Baseline \% of Max HR @ Stage 2 & & 1 & $-0.385^{*}$ & $-0.410^{*}$ \\
\hline Change in \% of Max HR @ Stage 1 & & & 1 & $0.823^{* * *}$ \\
\hline
\end{tabular}

Stage 1: 3.22 km/hr, no incline; Stage 2: 3.22 km/hr, $4 \%$ incline; ${ }^{*} p<0.01$; " $p<0.05$; **t $p<0.001$.

2 of baseline TT $(p=0.032)$ and positively correlated to baseline $\mathrm{VO}_{2 \max }(p=0.021)$, indicating men who lost weight had a large HR response to physical exertion and low aerobic fitness at baseline. Adjusting $\mathrm{VO}_{2 \max }$ for lean body mass, weight change was not significantly correlated $(p=0.837)$. Changes in weight from baseline to follow-up were positively correlated to PE at stage $1 \mathrm{TT}$ $(p=0.026)$ and stage 2 TT $(p=0.0006)$ (see Figure 2$)$. However, change in estimated $\mathrm{VO}_{2 \max }$ was not associated with weight change $(p=0.184)$.
Correlates of weight change and PE adjusted as a percentage of maximum HR are shown in Table 3; correlation coefficients and $p$-values are similar to unadjusted PE variables in Table 2. The multiple regression model for weight change is presented in Table 4 indicating change in PE at stage 2TT (decrease in heart rate predicting increased weight loss), days on study (more days in study predicting increased weight loss), and change in caloric consumption (greater caloric reduction predicting greater weight loss) were independently related to weight change. 
Table 4: Multiple regression model of weight change in men with prostate cancer participating in a presurgical weight loss trial $(\mathrm{n}$ $=28$ ).

\begin{tabular}{|l|l|l|l|l|l|}
\hline & R & B & Standardized beta & Partial r & P value \\
\hline Weight change $(\mathrm{kg}), \mathrm{p}<0.001$ & 0.792 & & & & \\
\hline Intercept & & 2.60 & & & \\
\hline Change in HR @ Stage 2 & & 0.19 & 0.509 & 0.635 & 0.0005 \\
\hline Days on study & & -0.08 & -0.453 & -0.589 & 0.0015 \\
\hline Change in caloric intake & & 0.002 & 0.315 & 0.457 & 0.0189 \\
\hline
\end{tabular}

\section{Discussion}

This is the first study exploring predictors of weight loss in men with prostate cancer. Despite small sample size, a reduction in HR during fitness testing predicted both a clinically and statistically significant weight loss, independent of age or baseline body mass; a finding that may help tailor future weight loss interventions in this population.

We hypothesized that physiological effort would be associated with weight loss; however these results suggest a much more dynamic relationship than predicted. The men exhibiting the highest levels of PE at baseline were more likely to lose weight over the course of the study. Physiological effort, or ease of locomotion, has previously been defined as a composite of fitness test $H R$, ventilation, and perceived exertion $[25,26]$. In this study, an increased HR at baseline alone preceded significant weight loss. This finding suggests there may be a potential disconnect between physiological and perceived effort in this population that may warrant further examination.

Participants in this study had baseline estimated VOsimilar to a cohort of prostate cancer survivors in an exercise intervention that yielded increases in $\mathrm{VO}_{2 \max }$ over ten weeks in both low and high intensity exercise regimens [27]. This sample of prostate cancer survivors may not have attained similar increases in $\mathrm{VO}_{2 \max }$ due to the wide range (3-to-13 weeks) of time on the study. We adjusted our estimates of $\mathrm{VO}_{2 \max }$ to adjust for potential changes attributed to loss of fat mass but did not detect longitudinal changes using this metric. Also, submaximal fitness testing was used in this study due to the increased risk of adverse events associated with the age and BMI status of the study participants. Recent research has reported that maximal cardiopulmonary exercise testing in localized prostate cancer survivors may have low reliability [25], yielding significant changes in $\mathrm{VO}_{2 \max }$ in 1-to-2 weeks. Results from this study indicate $\mathrm{VO}_{2 \max }$ may also not be an ideal measure of fitness for this population.

Men who lost the most weight experienced the greatest reductions in PE walking on an incline, i.e. had the greatest increase in ease of locomotion. The conversion of HR during the submaximal walks to percent of estimated maximum HR gives a better estimate of ease of movement, and thus improved the associations with PE and weight loss. This finding was consistent with re- sults from our previous studies in which we have shown that ease in locomotion is related to increased total energy expenditure and activity related energy expenditure $[17-19,28]$, as well as subsequent one year weight change in healthy subjects [16]. It is not known from these data whether improvement in ease of locomotion results in more physical activity and thus more weight loss, or whether weight loss causes an increase in ease of locomotion, or both. Future studies that assess PE at several time points throughout weight loss coupled with qualitative data may detangle this relationship. A 3-month physical activity intervention in breast cancer survivors significantly decreased the rate-pressure product, which positively associated with fatigue [26]; a link that may support ease of locomotion preceding more physical activity and potentially weight loss. Similarly, prostate cancer survivors in a 12-week training program significantly reduced their resting HR in comparison to controls [29], but decreases in resting HR were not observed for weight losers in this study.

In addition to the decrease in stage 2 PE positively associating with weight loss, multiple regression analysis indicated a significant relationship with days spent on study and change in caloric intake. When baseline $\mathrm{VO}_{2 \max }$ was added in to the regression, all other $\mathrm{p}$-values did not change significantly; therefore, $\mathrm{VO}_{2 \max }$ at baseline was not a confounding factor, but experimental intervention (dietary and exercise guidance) was important for promoting more rapid weight loss. The combined effect of decreased PE and reduction in caloric intake reinforce the need for both physical activity and diet modification for successful weight loss.

Men in this randomized controlled trial were motivated to lose weight, regardless of study arm allocation. Though only a small sample, this reinforces the concept of the teachable moment in cancer diagnosis and lifestyle change, as well as the potential impact of clinician encouragement to achieve a healthy weight $[3,30]$. The most profound finding in this secondary analysis is the association between physiological effort and the ability or propensity to initiate and continue physical activity achieving clinically meaningful weight loss in a matter of weeks. The most probable explanation for this relationship is that men with high baseline PE at early stages of the treadmill test were able to achieve greater caloric expenditure once they began exercising. This enabled attainment of a substantial caloric deficit which resulted in self-reinforcing, marked weight loss with minimal to moderate perceived effort. 


\section{Limitations}

While this is the first study reporting clinically significant associations with weight loss and HR at low level exercise in men with prostate cancer, there are limitations. First, $\mathrm{VO}_{2 \max }$ was estimated rather than directly tested. Additionally, there are generalizability limitations inherent with a small sample size. Translational potential of this exploratory study relies on replication in an appropriately powered intervention with the goal of increasing the probability of weight loss success. Future studies should also evaluate weight loss maintenance for men with prostate cancer that achieve shortterm success associated with decreased PE.

\section{Conclusion}

In conclusion, this study provides data to support an alternative means of predicting successful short-term weight loss in men with prostate cancer. These results suggest that increasing exercise efficiency is strongly associated with weight loss. Though the direction of causality was not determined in this study, both exercise and weight reduction for overweight and obese prostate cancer survivors have known benefits. While decreasing caloric intake is essential for long-term weight loss, aerobic exercise may accelerate and/or amplify success for many of these older men; oncologists and other health care providers should encourage both caloric restriction and aerobic physical activity among the overweight and obese prostate cancer patients for which they provide care.

\section{Acknowledgment}

This study was funded by National Institute of Health, National Cancer Institute (R21 CA161263, R25 CA047888, and P30 CA13148).

\section{Conflict of Interest}

The authors declare that they have no conflict of interest.

\section{Ethical Statement}

All procedures performed were in accordance with the ethical standards of the institutional and/or national research committee and with the 1964 Helsinki declaration and its later amendments or comparable ethical standards. Informed consent was obtained from all individual participants included in the study.

This trial is registered with the United States Clinical Trials Registry at clinicaltrials.gov. NCT01886677

\section{References}

1. Siegel RL, Miller KD, Jemal A (2016) Cancer statistics, 2016. CA Cancer J Clin 66: 7-30.

2. Allott EH, Masko EM, Freedland SJ (2013) Obesity and Prostate Cancer: Weighing the Evidence. Eur Urol 63: 800809.

3. Ligibel JA, Alfano CM, Courneya KS, Demark-Wahnefried
W, Burger RA, et al. (2014) American Society of Clinical Oncology Position Statement on Obesity and Cancer. J Clin Oncol 32: 3568-3574.

4. Greenlee H, Shi Z, Sardo Molmenti CL, Rundle A, Tsai WY (2016) Trends in Obesity Prevalence in Adults With a History of Cancer: Results From the US National Health Interview Survey, 1997 to 2014. J Clin Oncol 34: 3133-3140.

5. Rock CL, Doyle C, Demark-Wahnefried W, Meyerhardt J, Courneya KS, et al. (2012) Nutrition and physical activity guidelines for cancer survivors. CA Cancer J Clin 62: 243274.

6. Demark-Wahnefried W, Clipp EC, Lipkus IM, Lobach D, Snyder DC, et al. (2007) Main outcomes of the FRESH START trial: A sequentially tailored, diet and exercise mailed print intervention among breast and prostate cancer survivors. J Clin Oncol 25: 2709-2718.

7. Morey MC, Snyder DC, Sloane R, Cohen HJ, Peterson B, et al. (2009) Effects of home-based diet and exercise on functional outcomes among older, overweight long-term cancer survivors: Renew: A randomized controlled trial. JAMA 301: 1883-1891.

8. Jensen MD, Ryan DH, Apovian CM, Ard JD, Comuzzie AG, et al. (2013) 2013 AHA/ACC/TOS Guideline for the Management of Overweight and Obesity in Adults. A Report of the American College of Cardiology/American Heart Association Task Force on Practice Guidelines and The Obesity Society. Circulation 129: S102-S138.

9. Mohamad H, McNeill G, Haseen F, N'Dow J, Craig LC, et al. (2015) The Effect of Dietary and Exercise Interventions on Body Weight in Prostate Cancer Patients: A Systematic Review. Nutr Cancer 67: 43-60.

10. Weiss EP, Albert SG, Reeds DN, Kress KS, McDaniel JL, et al. (2016) Effects of matched weight loss from calorie restriction, exercise, or both on cardiovascular disease risk factors: A randomized intervention trial. Am J Clin Nutr 104: 576-586.

11. van Gemert WA, May AM, Schuit AJ, Oosterhof BY, Peeters PH, et al. (2016) Effect of Weight Loss with or without Exercise on Inflammatory Markers and Adipokines in Postmenopausal Women: The SHAPE-2 Trial, A Randomized Controlled Trial. Cancer Epidemiol Biomarkers Prev 25: 799-806.

12. Brunelli DT, Chacon-Mikahil MP, Gaspari AF, Lopes WA, Bonganha V, et al. (2015) Combined Training Reduces Subclinical Inflammation in Obese Middle-Age Men. Med Sci Sports Exerc 47: 2207-2215.

13. Duggan C, Tapsoba Jde D, Wang CY, McTiernan A (2016) Dietary Weight Loss and Exercise Effects on Serum Biomarkers of Angiogenesis in Overweight Postmenopausal Women: A Randomized Controlled Trial. Cancer Res 76: 4226-4235.

14. Hall KS, Morey MC, Dutta C, Manini TM, Weltman AL, et al. (2014) Activity-Related Energy Expenditure in Older Adults: A Call for More Research. Med Sci Sports Exerc 46: 23352340.

15. Hunter GR, Fisher G, Neumeier WH, Carter SJ, Plaisance EP (2015) Exercise Training and Energy Expenditure following Weight Loss. Med Sci Sports Exerc 47: 1950-1957.

16. Brock DW, Chandler-Laney PC, Alvarez JA, Gower BA, Gaesser GA, et al. (2010) Perception of exercise difficulty predicts weight regain in formerly overweight women. Obesity (Silver Spring) 18: 982-986.

17. Hunter GR, Bickel CS, Fisher G, Neumeier WH, McCarthy JP 
(2013) Combined aerobic and strength training and energy expenditure in older women. Med Sci Sports Exerc 45: 13861393.

18. Hunter GR, Fisher G, Bryan DR, Zuckerman PA (2012) Weight loss and exercise training effect on oxygen uptake and heart rate response to locomotion. J Strength Cond Res 26: 1366-1373.

19. Parker ND, Hunter GR, Treuth MS, Kekes-Szabo T, Kell SH, et al. (1996) Effects of strength training on cardiovascular responses during a submaximal walk and a weight-loaded walking test in older females. J Cardiopulm Rehabil 16: 56-62.

20. Demark-Wahnefried W, Nix JW, Hunter GR, Rais-Bahrami S, Desmond RA, et al. (2016) Feasibility outcomes of a presurgical randomized controlled trial exploring the impact of caloric restriction and increased physical activity versus a wait-list control on tumor characteristics and circulating biomarkers in men electing prostatectomy for prostate cancer. BMC Cancer 16: 61.

21. Kohl HW, Gibbons LW, Gordon NF, Blair SN (1990) An empirical evaluation of the ACSM guidelines for exercise testing. Med Sci Sports Exerc 22: 533-539.

22. De Keyzer W, Huybrechts I, De Vriendt V, Vandevijvere S, Slimani N, et al. (2011) Repeated 24-hour recalls versus dietary records for estimating nutrient intakes in a national food consumption survey. Food Nutr Res 55.

23. Subar AF, Kirkpatrick SI, Mittl B, Zimmerman TP, Thompson FE, et al. (2012) The Automated Self-Administered 24Hour Dietary Recall (ASA24): A Resource for Researchers, Clinicians and Educators from the National Cancer Institute. J Acad Nutr Diet 112: 1134-1137.
24. Bodner-Montville J, Ahuja JKC, Ingwersen LA, Haggerty ES, Enns CW, et al. (2006) USDA Food and Nutrient Database for Dietary Studies: Released on the web. J Food Comp Anal 19: S100-S107.

25. Scott JM, Hornsby WE, Lane A, Kenjale AA, Eves ND, et al. (2015) Reliability of maximal cardiopulmonary exercise testing in men with prostate cancer. Med Sci Sports Exerc 47: 27-32.

26. Carter SJ, Hunter GR, McAuley E, Courneya KS, Anton PM, et al. (2016) Lower rate-pressure product during submaximal walking: A link to fatigue improvement following a physical activity intervention among breast cancer survivors. J Cancer Surviv 10: 927-934.

27. Martin EA, Battaglini CL, Hands B, Naumann F (2015) Higher-Intensity Exercise Results in More Sustainable Improvements for VO2peak for Breast and Prostate Cancer Survivors. Oncol Nurs Forum 42: 241-249.

28. Hunter GR, Weinsier RL, Zuckerman PA, Darnell BE (2004) Aerobic fitness, physiologic difficulty and physical activity in Black and White women. Int J Obes Relat Metab Disord 28: 1111-1117.

29. Gaskin CJ, Fraser SF, Owen PJ, Craike M, Orellana L, et al. (2016) Fitness outcomes from a randomised controlled trial of exercise training for men with prostate cancer: The ENGAGE study. J Cancer Surviv 10: 972-980.

30. Demark-Wahnefried W, Jones LW (2008) Promoting a Healthy Lifestyle among Cancer Survivors. Hematol Oncol Clin North Am 22: 319-342. 